\title{
Capture and scanning electron microscopy of individual snow crystals
}

\author{
E. W. WOLFF \\ British Antarctic Survey, Natural Environment Research Council, Madingley Road, Cambridge CB3 OET, England \\ A. P. REID \\ Institute of Environmental and Biological Sciences, University of Lancaster, Lancaster LA1 4 YQ England
}

\begin{abstract}
A snow crystal has been successfully collected on to a scanning electron microscope (SEM) stub in central Greenland. It was preserved at liquidnitrogen temperature for 5 months, prior to examination in the SEM. This is believed to be the first time a snow crystal has been observed directly in the SEM and offers some new experimental methods for understanding crystals and their chemistry.
\end{abstract}

\section{INTRODUGTION}

Individual snow crystals have been examined for some decades and recorded by photomicroscopy (e.g. Bentley and Humphreys, 1931). Direct observation is rather difficult, because samples evaporate and metamorphose rapidly after collection. Many studies have circumvented this problem by making replicas of crystals in a plastic film and then examining the replicas. In particular, snow crystals have been classified and the different shapes have been identified with various temperature and humidity conditions during their growth (Nakaya, 1954; Hobbs, 1974). Studies have been made of the best plastics and solvents to use for making replicas (Takahashi and Fukuta, 1987).

Replicas can also be used for examining snow crystals in the electron microscope (e.g. Stoyanova and others, 1987). This will give the morphology at high resolution and can also be used in conjunction with an X-ray microanalyser to analyse the chemical content of the central nucleus of each crystal (Kikuchi and others, 1982). In earlier work, snow crystals had been captured on collodion-coated electron-microscope grids. After evaporation, electron-diffraction patterns were used to determine the chemical composition of the central nuclei (Kumai, 1976).

While the replica methods have proved extremely powerful, they do not allow observation of the original snow crystal and, for this reason, some detail of crystal shape must be lost. We have shown that it is possible to observe natural ice from the polar ice sheets in an SEM using cryogenic techniques (Mulvaney and others, 1988; Wolff and others, 1988). In this study, we report a technique for capturing and preserving snow crystals for subsequent direct examination in the SEM.

\section{COLLEGTION OF SNOW GRYSTALS}

Snow crystals were collected at the GRIP (Greenland Icecore Project) drilling site at Summit in central Greenland $\left(72^{\circ} 34^{\prime} \mathrm{N}, 37^{\circ} 38^{\prime} \mathrm{W}, 3240 \mathrm{~m}\right.$ a.s.l. $)$ during July 1991. Earlier tests in Antarctica had indicated some of the conditions that favour collection.
Leit-C conducting carbon cement for SEM was spread on to Jeol $10 \mathrm{~mm} \mathrm{Al} \mathrm{SEM} \mathrm{stubs} \mathrm{in} \mathrm{the} \mathrm{under-}$ ground science trench at $-15^{\circ} \mathrm{C}$. The solvent (xylene) of the cement was allowed to evaporate for a few minutes until the cement reached a desired consistency. If the cement is too wet, snow crystals submerge on impact; if it is too dry, they will not attach at all.

The stubs were then taken to the surface and exposed to snowfall on a horizontal surface about $1 \mathrm{~m}$ above the ground. They were observed regularly over the next few minutes to see whether they had accumulated any snow crystals. It is necessary that there is a reasonably high rate of snowfall, since the stubs can be left for only a few minutes before the cement is too dry for the crystals to attach. It is easiest to collect in low wind speeds. The temperature must be below about $-5^{\circ} \mathrm{C}$; above this temperature, the cement, which is coloured black, warms and melts the snow crystals. Naturally, the colder the temperature, the longer the stubs can be left before the cement dries. Stubs should be handled only with cool tweezers to avoid warming them.

During snowfalls on 13 July 1991 and 15 July 1991, several stubs were observed to have collected snow crystals. The temperature at the times of collection was between $-5^{\circ}$ and $-10^{\circ} \mathrm{C}$. On both dates, several of the crystals were hexagons of 2-4 mm diameter; needles and aggregates were also captured. Once a stub was seen to have a snow crystal present on it, it was immediately placed with the tweezers on to the upturned lid of a small snap-top polyethylene vial. The other half of the vial, which had a piece of cotton threaded through it, was snapped closed and the vial was lowered (using the cotton) into a cryogenic dry shipping vessel (Statebourne DXR 3). The main requirements for the vials are that they are leaktight and that it is easy to remove the stub later (which is why stubs are placed on the shallow lid of the vial).

The dry shipper is a Dewar, most of whose volume is an absorbent that absorbs liquid nitrogen so that it can be transported without spillage. Sample vials are lowered into a central cylinder a few centimetres in diameter. Once properly filled, it contains 3.21 of liquid nitrogen and has a static holding time of $21 \mathrm{~d}$. In this case, the 
vessel was filled in England on 5 July 1991, carried by air to Summit and was topped up on return to England on 22 July 1991 and regularly thereafter. It was observed that cryogen was still present before the vessel was topped up.

From the time the snow crystal landed on the SEM stub until the time it was immersed into an atmosphere at liquid-nitrogen temperature was normally about $30 \mathrm{~s}$. From this point on, the samples were always at liquidnitrogen temperature $\left(-195.8^{\circ} \mathrm{C}\right.$ if fully equilibrated at atmospheric pressure). It can be assumed that the cement froze solid soon after the vials were lowered into the shipper. Extrapolation of tabulated values suggests that, at $-195.8^{\circ} \mathrm{C}$, the vapour pressure above the ice will be well below $10^{-20} \mathrm{~N} \mathrm{~m}^{-2}$. Comparing this with vapour pressures and measured sublimation rates (personal communication from $\mathrm{K}$. Oates) at higher temperatures suggests that sublimation from the ice, once it was in the shipper, will have had no effect even at the nm scale. Water vapour from the air should be removed near the top of the shipping vessel and so should not condense on to the ice. Except immediately after filling, there is liquid nitrogen only in the absorbent and the vials anyway appear to be rather leaktight, so that until the analysis stage the ice is in a cold atmosphere but is not submerged in liquid nitrogen.

\section{ELEGTRON MICROSCOPY}

The shipping vessel was kept topped up until analysis on 10 December 1991, 5 months after collection. In the SEM laboratory, each vial was transferred rapidly (about $2 \mathrm{~s}$ ) to a beaker of liquid nitrogen. It was held below the surface and the two parts of the vial separated, so that the stub could be removed from the vial. From here onwards, the procedure was identical to that we have used before (Mulvaney and others, 1988; Wolff and others, 1988). The stub was transferred under a cap to a cryogenically cooled pre-chamber, coated with $\mathrm{Al}$ to make it conducting and then transferred to the cold stage of the electron microscope at below $-160^{\circ} \mathrm{C}$. Samples were examined with an accelerating voltage of $15 \mathrm{kV}$ and energydispersive X-ray analysis was available.

\section{RESULTS}

A number of stubs were examined. It should be noted that the many "white particles" seen on the SEM images are mainly condensed frost from the liquid nitrogen. They are easily identified by their shape, lack of chemical signal and tendency to charge due to poor contact to the stub.

On several stubs, no ice was present. However, an impression of ice crystals was visible on the surface (e.g. Fig. 1). It seems likely that the crystals had not been retained when the Leit-C froze. In that case, they may have floated free when the stubs were eventually submerged in liquid nitrogen in the laboratory.

On one stub, a hexagonal ice crystal was clearly visible (Fig. 2). Much of the crystal appears to be partly submerged under the cement, but the bottom right is clearly above the cement surface. This may well explain why the crystal was retained on this stub; it was held firmly by the submerged part.

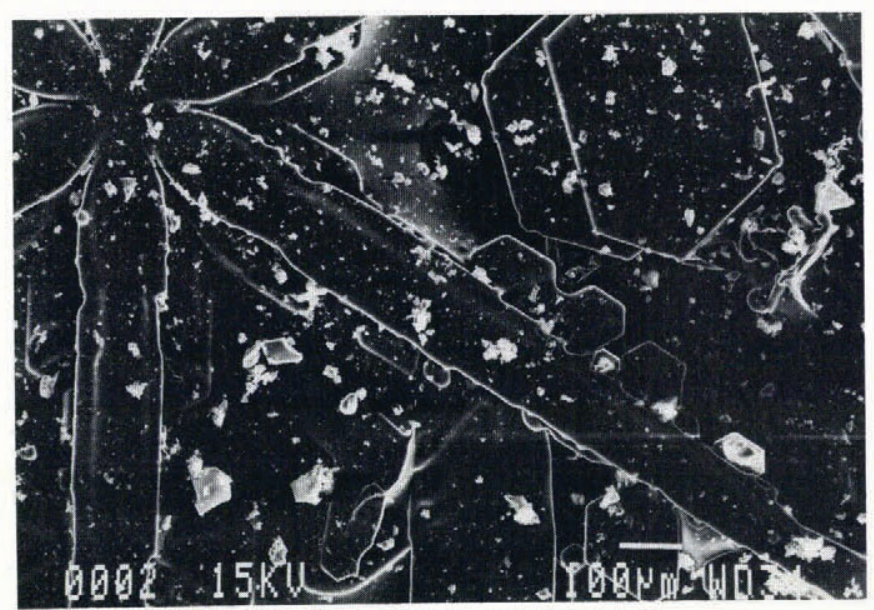

Fig. 1. SEM photograph showing the impression of several snow crystals in Leit-C cement.

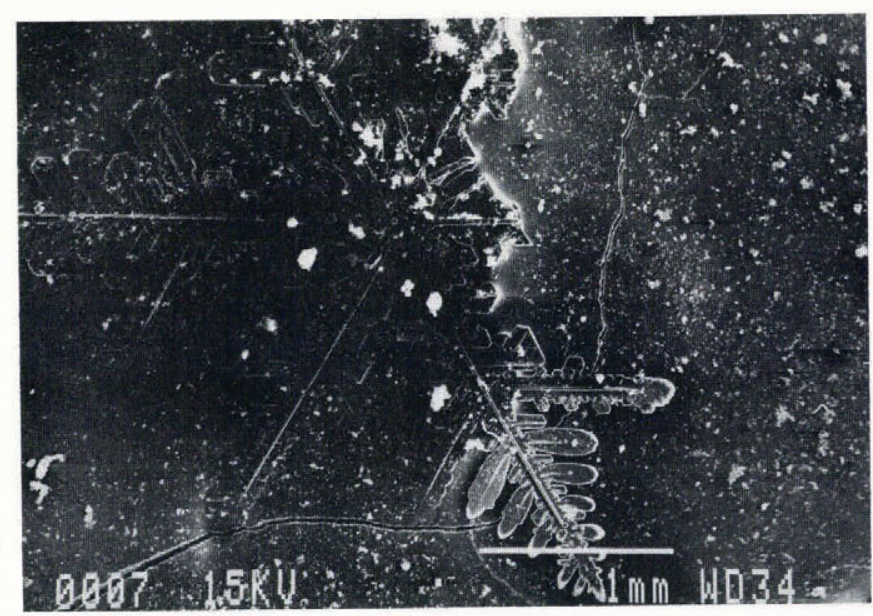

Fig. 2. SEM image of a captured snow crystal.

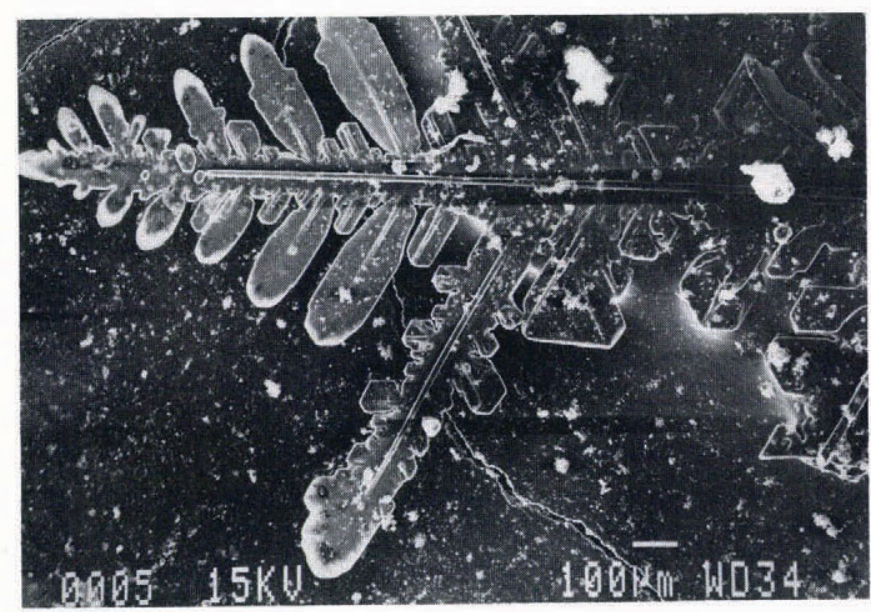

Fig. 3. SEM image of an exposed part of a captured snow crystal.

The part that is above the surface was examined and shows considerable detail in places (Fig. 3). Although there is rounding of some features, others are wellpreserved (Fig. 4). The rounding of certain features may have occurred on the stub after capture, but before transfer to the cold shipping vessel, since no significant changes can have taken place during storage. 


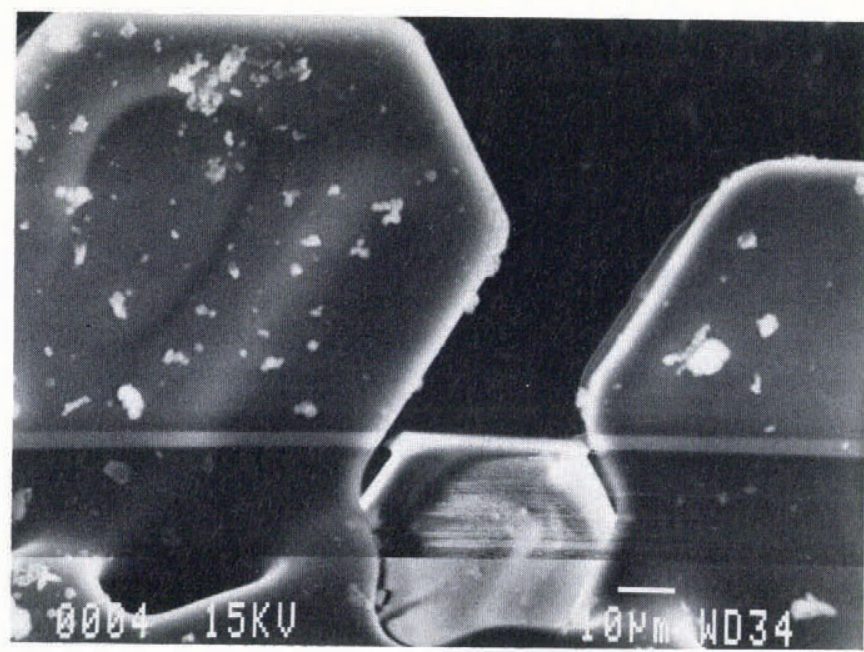

Fig. 4. SEM detail of a snow crystal.

\section{CONGLUSIONS}

It is possible to collect a snow crystal directly on to an SEM stub, preserve it for a period of 5 months with only minimal change and then observe it in the SEM. However, it must be said that the conditions leading to capture of the crystal were rather special and it would be preferable to find a more certain method.

Other cements might be tried, but there are no obvious candidates that are more likely to retain the crystal. Crystals could be collected directly into a vial (not on to a stub) and attached later but it would be hard to find, handle and attach the crystal even in the laboratory. A better solution might be to push one side of each crystal deliberately under the cement. This would mean that not all of the crystal can be examined.

If crystals can be captured and observed directly in the SEM, there are a number of advantages. First, it is likely that a greater degree of detail will be retained than is the case with replica techniques. It should be possible to sublime the ice (if it has not been coated) while observing it in the SEM and then to carry out elemental X-ray analysis of the central nucleus and any other material remaining. This is even more direct than the usual methods of analysing nuclei. It should also be possible to make direct analyses of rime droplets attached to the snow crystal (none were observed in the case we are reporting). For chemistry to be observed above the detection limit, significant localization of impurity is necessary; a thin film of acid over the entire crystal surface would be below the detection limit of the X-ray analysis system.

Although it is unlikely to be amenable to routine use, this could provide a useful occasional method for studying snow crystals and their nuclei. Since the chemical record in ice cores is eventually derived from the sum of individual snow crystals, modified after deposition, such studies are one step on the way to interpreting the ice-core record.

\section{ACKNOWLEDGEMENTS}

This work is a contribution to the Greenland Icecore Project (GRIP), a European Science Foundation programme with eight nations collaborating to drill through the central part of the Greenland ice sheet. J. Moore helped with the collection of the crystals and the SEM study. R. Mulvaney helped to design the vials and test the transport vessel.

\section{REFERENCES}

Bentley, W. A. and W.J. Humphreys. 1931. Snow crystals. New York, McGraw-Hill.

Hobbs, P. V. 1974. Ice physics. Oxford, Clarendon Press.

Kikuchi, K., M. Murakami and Y. Sanuki. 1982. Preliminary measurements of the center nucleus of snow crystals using an energy dispersive X-ray microanalyzer. Mem. Natl. Inst. Polar Res., Spec. Issue $24,157-174$

Kumai, M. 1976. Identification of nuclei and concentrations of chemical species in snow crystals sampled at the South Pole. F. Atmos. Sci., 33(5), 833-841.

Mulvaney, R., E. W. Wolff and K. Oates. 1988. Sulphuric acid at grain boundaries in Antarctic ice. Nature, 331(6153), 247-249.

Nakaya, U. 1954. Snow crystals, natural and artificial. Cambridge, MA, Harvard University Press.

Stoyanova, V., N. Genadiyev and D. Nenow. 1987. An application of the replica method for SEM-study of the ice crystal instability. $\mathcal{F}$. Phys. (Paris), 48, Collog. Cl, 375-381. (Supplément au 3.)

Takahashi, T. and N. Fukuta. 1987. Application of common plastic solutions for ice crystal replication. F. Phys. (Paris), 48, Collog. C1 405-411. (Supplément au 3.)

Wolff, E.W., R. Mulvaney and K. Oates. 1988. The location of impurities in Antarctic ice. Ann. Glaciol., 11, 194-197.

The accuracy of references in the text and in this list is the responsibility of the authors, to whom queries should be addressed. 